\title{
Correlates of Omani adults' physical inactivity and sitting time
}

\author{
Ruth M Mabry ${ }^{1,2, *}$, Elisabeth AH Winkler ${ }^{2}$, Marina M Reeves ${ }^{2}$, Elizabeth $G$ Eakin $^{2}$ and \\ Neville Owen ${ }^{3}$ \\ 'Office of the WHO Representative, PO Box 476, Al Atheiba, Postal Code 130, Muscat, Oman: ${ }^{2}$ Cancer \\ Prevention Research Centre, School of Population Health, The University of Queensland, Brisbane, Australia: \\ ${ }^{3}$ Baker IDI Heart and Diabetes Institute, Melbourne, Australia
}

Submitted 17 November 2011: Final revision received 14 March 2012: Accepted 30 April 2012: First published online 25 May 2012

\begin{abstract}
Objective: To inform public health approaches for chronic disease prevention, the present study identified sociodemographic, anthropometric and behavioural correlates of work, transport and leisure physical inactivity and sitting time among adults in Oman.

Design: Cross-sectional study using the WHO STEPwise study methodology.

Setting: Sur City, Oman.

Subjects: Men and women aged 20 years and older ( $n$ 1335) in the Sur City Healthy Lifestyle Study who had complete data for demographic variables (gender, age, education, work status and marital status), BMI and behavioural risk factors - smoking and dietary habits plus physical inactivity and sitting time (the outcome variables).

Results: The highest level of physical inactivity was in the leisure domain (55.4\%); median sitting time was about $2 \mathrm{~h} / \mathrm{d}$. Gender-stratified logistic regression models found that the statistically significant $(P<0.05)$ correlates of inactivity (in one or more domains) were age, work status and fruit and vegetable intake in women, and age, education, work status, marital status and BMI in men. Gender-stratified linear regression models found that the statistically significant correlates of sitting time were age, work status and BMI in women and education in men.

Conclusions: Findings suggest that public health interventions need to be gender responsive and focus on domain-specific physical inactivity. In the Omani context, this might include gender-segregated exercise facilities to promote leisure physical activity among women and walking-friendly environmental initiatives to promote transport physical activity among men. Further evidence on barriers to physical activity and factors that influence prolonged sitting is required to develop relevant public health interventions.
\end{abstract}

Physical inactivity is a key modifiable risk factor for CVD, type 2 diabetes and the metabolic syndrome, a precursor of these diseases ${ }^{(1-3)}$. Sedentary behaviour (too much sitting, as distinct from too little exercise) is a recently identified health risk that has shown associations with the metabolic syndrome and its components in crosssectional $^{(4-6)}$ and prospective studies ${ }^{(7,8)}$, mostly conducted in Western populations. Evidence from Oman demonstrates associations of physical inactivity, particularly in the work and transport domains, and sitting time with higher odds of the metabolic syndrome, although these associations are not completely independent ${ }^{(9)}$. Given the rising prevalences of obesity, type 2 diabetes, CVD and other chronic diseases in Oman $^{(10)}$, reducing physical inactivity and prolonged sitting are public health priorities.

Recent reviews have identified lower educational attainment, lower income and older age to be consistently associated with physical inactivity, with evidence primarily from adults in developed countries ${ }^{(11,12)}$. Less is known about the prevalence and correlates of sitting time ${ }^{(13)}$. A recent review using data from twenty developed and developing countries identified older age and higher educational attainment to be associated with higher overall sitting time ${ }^{(14)}$.

Using a cross-sectional population-representative data set, the present study examined the sociodemographic, anthropometric and behavioural correlates of physical inactivity in the work, transport and leisure domains, and of sitting time, among Omani adults.

\section{Methods}

\section{Overview of the Sur Healthy Lifestyle Survey}

The Sur Healthy Lifestyle Survey is a cross-sectional survey of Omani men and non-pregnant women aged 20 years or older residing in the city of Sur; data collection took place 
from March to June 2006. It followed the WHO STEPwise methodology, a standard method of data collection on key risk factors for chronic diseases ${ }^{(15)}$. The Arabic version of the WHO STEPwise instrument was adapted to the local context using the local Arabic dialect, incorporating additional questions on dietary intake and deleting the section on alcohol use due to the sensitivity of asking this information. A multistage sampling design was used where a random sample of 1700 houses was selected from 191 census clusters in Sur City and an individual was randomly selected in each selected household from all eligible household members. A high proportion of those selected completed the household interview and clinical measures ( $n 1373 ; 80 \cdot 8 \%$ ). Ethical approval for the survey was granted by the Ministry of Health Research Committee. Participants with complete data for all key variables ( $n$ 1335; 97.2\%) were included in the present analyses. Only limited information on the study sampling frame and response rates was available. The sample differed in age and gender distribution from the Sur City population around the time of the survey (based on the most proximal National Census) ${ }^{(16)}$. Thus, weights for each gender-specific 5-year age band were derived to 'reweight' the sample to the reference population (Sur City population, 2003) ${ }^{(16)}$.

\section{Data collection}

The adapted Arabic version of the WHO STEPwise instrument was used to collect data for demographic variables (gender, age, education, work status and marital status), overweight and obesity, and behavioural risk factors (smoking, dietary habits, physical activity and sitting time). Demographic and behavioural data were collected using face-to-face household and individual interviews. Anthropometric measurements (height and weight) were taken following the WHO protocol ${ }^{(15)}$ during the clinic visits. Questionnaires were reviewed for quality prior to data entry into the SPSS statistical software package version 9.

\section{Potential correlates and outcome variables}

The dependent variables were domain-specific physical inactivity and total sitting time measured using the sixteen-item Global Physical Activity Questionnaire (GPAQ) and scored as per standard protocols ${ }^{(17)}$. GPAQ, developed by $\mathrm{WHO}$ and incorporated within the WHO STEPwise instrument, measures physical activity (intensity, duration and frequency) performed in three domains - work (paid and unpaid including housework), transport (walking and cycling) and leisure - as well as total sitting time. Studies have confirmed the validity and reliability of this instrument across diverse populations, but not Arab populations ${ }^{(18-20)}$. Physical activity was estimated by calculating energy expenditure using the metabolic equivalent of task (MET), the ratio of specific physical activity metabolic rates compared with the RMR ( 1 MET is equivalent to the energy cost of sitting quietly, $4 \cdot 184 \mathrm{~kJ}(1 \mathrm{kcal}) / \mathrm{kg}$ per h).
Total MET-min/d was calculated for each domain by first multiplying MET values by reported minutes, with moderate-intensity and transport activities assigned a value of 4 MET and vigorous-intensity activities assigned a value of $8 \mathrm{MET}$, and then adding the total MET-min of vigorous- and moderate-intensity activities performed.

Domain-specific activity variables did not follow a distribution that could easily be modelled and ordinal logistic regression assumptions were not met; thus, binary variables were used to define each physical inactivity outcome examined. A substantial proportion of participants did no transport and leisure physical activity; these outcomes were examined as none $v$. any, since inactivity (doing no activity) was of interest. All participants did at least some physical activity in the work domain; thus, this was examined as the lowest quartile ('inactive') $v$. the three higher quartiles of work physical activity in the Sur City population. The GPAQ instrument includes a single item on total sitting time: 'Over the past $7 \mathrm{~d}$, how much time did you spend sitting or reclining on a typical day?', with responses reported as hours and/or minutes per day. Since the distribution of sitting time was non-normal, the natural logarithm for sitting time was used.

The independent variables included gender, age (20-29 years, 30-39 years, $\geq 40$ years), education (less than secondary education, secondary education, postsecondary education), marital status (married, not married), employment status (employed, not employed), BMI ( $\mathrm{kg} / \mathrm{m}^{2}$; calculated as weight in kilograms divided by the square of height in metres), smoking status (current smoker, nonsmoker) and intake of fruits and vegetables ( $<2$ servings/d, $\geq 2$ servings/d). Inclusion and categorization of variables was based on bivariate and regression analysis to ensure that there was sufficient power for the regression models and adequate numbers in all categories.

\section{Data analysis}

Data were analysed using the STATA statistical software package version 11. Independent associations of correlates of each physical inactivity outcome were estimated using binary logistic regression. Results are reported as odds ratios with $95 \%$ confidence intervals. Independent associations of correlates of sitting time were estimated using linear regression. Results are reported as exponentiated beta coefficients with $95 \%$ confidence intervals; these can be interpreted as ratios, sometimes termed 'relative rates'. Whenever a significant correlate was identified, marginal probabilities (logistic regression) or means (linear regression) were also reported from these models to highlight the absolute prevalence of inactivity or mean sitting time (adjusted for confounders) in the population subgroups that had been identified as more inactive, or having higher sitting times, than their counterparts. All models were weighted to the Sur City population and included all correlates studied (age, education, employment status, marital status, daily number of vegetable and fruit servings, 
BMI; men's models also included smoking). Models (without weighting) were tested for gender and age interactions. Statistical significance was set at $P<0 \cdot 05$. Twofold higher or lower odds (logistic regression) or relative rates (linear regression) were considered potentially sizeable differences across categories (or across a meaningful exposure dose for continuous variables). As is the case for the $P<0.05$ threshold for significance, these cut-offs are arbitrary but can be taken to indicate that associations are likely.

\section{Results}

The sample was young (mean age $36 \cdot 3$ (SD $12 \cdot 5$ ) years) with more than half having at least a high school education $(57 \cdot 7 \%)$ and nearly two-thirds being married (61.6\%; see Table 1). In addition, the sample had a mean BMI in the overweight category $\left(28 \cdot 0(\mathrm{SD} 6 \cdot 4) \mathrm{kg} / \mathrm{m}^{2}\right)$. Overall, the highest level of physical inactivity was in the leisure domain $(55.4 \%)$; the median sitting time was about $2 \mathrm{~h} / \mathrm{d}$.

Due to many statistically significant gender interactions, results are presented stratified by gender. Tables 2 and 3 present the independent correlates of men's and women's work, transport and leisure inactivity.

In men, none of the potential correlates examined showed significant associations with work inactivity.
For transport inactivity, age $(P$ for trend $=0 \cdot 02$ ) and BMI $(P<0 \cdot 01)$ were significant correlates; for age, there was no clear increasing or decreasing trend and each additional BMI unit was significantly associated with a $6 \%$ higher odds of transport inactivity (95\% CI 1, 10\%). Significantly higher odds of leisure inactivity were seen in men with lower levels of education $(P$ for trend $=0.03$ ), men who were not employed $v$. employed $(P<0 \cdot 05)$ and married men $v$. unmarried $(P<0 \cdot 01)$. Further examining adjusted prevalence across the identified correlates revealed some population subgroups who were commonly inactive considering the overall prevalence of inactivity (95\% CI) in men in Sur City: $31 \cdot 2$ (95\% CI $27 \cdot 5,35 \cdot 0) \%$ for work inactivity, $23 \cdot 8(95 \% \mathrm{CI} 20 \cdot 3,27 \cdot 2) \%$ for transport inactivity and 41.7 (95\% CI $37 \cdot 7,45 \cdot 7) \%$ for leisure inactivity. Adjusted prevalence $(95 \% \mathrm{CI})$ of leisure inactivity was $52 \cdot 1$ (95\% CI $41 \cdot 9,62 \cdot 2) \%$ in men who were not employed, $48 \cdot 6$ (95\% CI $41 \cdot 6,55 \cdot 5) \%$ in married men and $47 \cdot 9$ (95\% CI $39 \cdot 8,56 \cdot 2) \%$ in men with less than secondary education. Adjusted prevalence $(95 \% \mathrm{CI})$ of transport inactivity was 32.6 (95\% CI 23.6, 41.7) \% in men who were obese $\left(\mathrm{BMI} \geq 30 \cdot 0 \mathrm{~kg} / \mathrm{m}^{2}\right)$ and $31 \cdot 0$ (95\% CI $\left.23 \cdot 2,38 \cdot 9\right) \%$ in men aged 30-39 years.

In women, age was the only potential correlate significantly associated with work inactivity ( $P$ for trend $=0 \cdot 03$ ); specifically, those aged $\geq 40$ years had more than double the odds of being inactive compared with the youngest

Table 1 Selected characteristics of participants in the Sur Healthy Lifestyle Survey, Oman, 2006

\begin{tabular}{|c|c|c|c|c|c|c|}
\hline & \multicolumn{2}{|r|}{ Men ( $n$ 591) } & \multicolumn{2}{|c|}{ Women ( $n$ 744) } & \multicolumn{2}{|c|}{ Total $(n$ 1335) } \\
\hline & $\%$ & Unweighted $n$ & $\%$ & Unweighted $n$ & $\%$ & Unweighted $n$ \\
\hline \multicolumn{7}{|l|}{ Age (years) } \\
\hline Mean & \multicolumn{2}{|r|}{$37 \cdot 7$} & \multicolumn{2}{|r|}{$35 \cdot 2$} & \multicolumn{2}{|r|}{$36 \cdot 3$} \\
\hline $\mathrm{SD}$ & \multicolumn{2}{|r|}{$13 \cdot 5$} & \multicolumn{2}{|r|}{$11 \cdot 4$} & \multirow{2}{*}{\multicolumn{2}{|c|}{$12 \cdot 5$}} \\
\hline \multicolumn{5}{|l|}{ Education } & & \\
\hline Less than secondary & $41 \cdot 1$ & 243 & $43 \cdot 2$ & 321 & $42 \cdot 3$ & 564 \\
\hline Secondary & $37 \cdot 4$ & 221 & $21 \cdot 1$ & 157 & $28 \cdot 3$ & 378 \\
\hline Post-secondary & $21 \cdot 5$ & 127 & $35 \cdot 8$ & 266 & $29 \cdot 4$ & 393 \\
\hline \multicolumn{7}{|l|}{ Work status } \\
\hline Employed & $78 \cdot 0$ & 461 & $41 \cdot 7$ & 310 & $57 \cdot 8$ & 771 \\
\hline Not employed & $22 \cdot 0$ & 130 & $58 \cdot 3$ & 434 & $42 \cdot 3$ & 564 \\
\hline \multicolumn{7}{|l|}{ Marital status } \\
\hline Not married & 33.5 & 198 & $42 \cdot 3$ & 315 & $38 \cdot 4$ & 513 \\
\hline Married & $66 \cdot 5$ & 393 & $57 \cdot 7$ & 429 & $61 \cdot 6$ & 822 \\
\hline \multicolumn{7}{|l|}{ Fruit and vegetable intake } \\
\hline$<2$ servings/d & $52 \cdot 5$ & 310 & $48 \cdot 5$ & 361 & $50 \cdot 3$ & 671 \\
\hline$\geq 2$ servings $/ d$ & $47 \cdot 6$ & 281 & $51 \cdot 5$ & 383 & $49 \cdot 7$ & 664 \\
\hline \multicolumn{7}{|l|}{ Currently smoke } \\
\hline No & $79 \cdot 2$ & 468 & $99 \cdot 7$ & 742 & $90 \cdot 6$ & 1210 \\
\hline Yes & $20 \cdot 8$ & 123 & 0.3 & 2 & $9 \cdot 36$ & 125 \\
\hline \multicolumn{7}{|l|}{ BMI $\left(\mathrm{kg} / \mathrm{m}^{2}\right)$} \\
\hline Mean & \multirow{2}{*}{\multicolumn{2}{|c|}{$\begin{array}{r}26 \cdot 4 \\
5 \cdot 0\end{array}$}} & \multicolumn{2}{|r|}{$29 \cdot 2$} & \multicolumn{2}{|r|}{$28 \cdot 0$} \\
\hline SD & & & & $7 \cdot 0$ & & $6 \cdot 4$ \\
\hline \multicolumn{7}{|l|}{ Physical inactivity } \\
\hline Low workt & $32 \cdot 1$ & 190 & $18 \cdot 4$ & 137 & $24 \cdot 5$ & 327 \\
\hline No transport & $25 \cdot 5$ & 151 & $34 \cdot 4$ & 256 & $30 \cdot 5$ & 407 \\
\hline No leisure & $43 \cdot 8$ & 259 & $64 \cdot 5$ & 480 & $55 \cdot 4$ & 739 \\
\hline \multicolumn{7}{|l|}{ Sitting $(\mathrm{min} / \mathrm{d})$} \\
\hline Median & \multirow{2}{*}{\multicolumn{2}{|c|}{$\begin{array}{c}180 \\
120,300\end{array}$}} & \multirow{2}{*}{\multicolumn{2}{|c|}{$\begin{array}{c}120 \\
60,199\end{array}$}} & \multirow{2}{*}{\multicolumn{2}{|c|}{$\begin{array}{c}120 \\
90,240\end{array}$}} \\
\hline 25th, 75th percentile & & & & & & \\
\hline
\end{tabular}

tLow work $=$ lowest quartile. 
Table 2 Correlates of domain-specific physical inactivity in Omani men ( $n$ 591), Sur Healthy Lifestyle Survey, 2006+‡

\begin{tabular}{|c|c|c|c|c|c|c|c|c|c|}
\hline & \multicolumn{3}{|c|}{ Work } & \multicolumn{3}{|c|}{ Transport } & \multicolumn{3}{|c|}{ Leisure } \\
\hline & $n$ (inactive) & OR & $95 \% \mathrm{Cl}$ & $n$ (inactive) & OR & $95 \% \mathrm{Cl}$ & $n$ (inactive) & OR & $95 \% \mathrm{Cl}$ \\
\hline \multicolumn{10}{|l|}{ Age } \\
\hline 20-29 years $(n 197)$ & 57 & $1 \cdot 00$ & Ref. & 41 & $1 \cdot 00$ & Ref. & 63 & $1 \cdot 00$ & Ref. \\
\hline $30-39$ years $(n 177)$ & 58 & $1 \cdot 37$ & $0 \cdot 80,2 \cdot 35$ & 63 & $1 \cdot 50$ & $0 \cdot 86,2 \cdot 61$ & 76 & $1 \cdot 33$ & $0 \cdot 80,2 \cdot 21$ \\
\hline$\geq 40$ years $(n 217)$ & 75 & $1 \cdot 47$ & $0 \cdot 76,2 \cdot 84$ & 47 & $0 \cdot 71$ & $0 \cdot 36,1 \cdot 40$ & 120 & $1 \cdot 43$ & $0.79,2.59$ \\
\hline$P$ for trend & & 0.44 & & & 0.02 & & & $0 \cdot 44$ & \\
\hline \multicolumn{10}{|l|}{ Education } \\
\hline Less than secondary ( $n$ 243) & 74 & $1 \cdot 00$ & Ref. & 61 & $1 \cdot 00$ & Ref. & 130 & $1 \cdot 00$ & Ref. \\
\hline Secondary $(n$ 221) & 78 & $1 \cdot 21$ & $0 \cdot 72,2 \cdot 05$ & 54 & 0.69 & $0 \cdot 40,1 \cdot 18$ & 92 & 0.75 & $0.47,1 \cdot 21$ \\
\hline $\begin{array}{l}\text { Post-secondary ( } n \text { 127) } \\
P \text { for trend }\end{array}$ & 38 & $\begin{array}{l}1 \cdot 18 \\
0 \cdot 75\end{array}$ & $0 \cdot 65,2 \cdot 15$ & 36 & $\begin{array}{l}1 \cdot 02 \\
0.29\end{array}$ & $0.55,1 \cdot 89$ & 37 & $\begin{array}{l}0.45^{\star *} \\
0.03\end{array}$ & $0 \cdot 25,0.80$ \\
\hline \multicolumn{10}{|l|}{ Work status } \\
\hline Employed ( $n$ 461) & 139 & $1 \cdot 00$ & Ref. & 124 & $1 \cdot 00$ & Ref. & 183 & $1 \cdot 00$ & Ref. \\
\hline Not employed ( $n 130)$ & 51 & $1 \cdot 35$ & $0 \cdot 83,2 \cdot 20$ & 27 & 0.98 & $0.55,1.72$ & 76 & $1 \cdot 83^{*}$ & $1 \cdot 13,2 \cdot 97$ \\
\hline \multicolumn{10}{|l|}{ Marital status } \\
\hline Not married ( $n$ 198) & 62 & $1 \cdot 00$ & Ref. & 43 & $1 \cdot 00$ & Ref. & 65 & $1 \cdot 00$ & Ref. \\
\hline Married (n 393) & 128 & 0.92 & $0.54,1.55$ & 108 & $1 \cdot 36$ & $0 \cdot 78,2 \cdot 38$ & 194 & $1.98^{\star *}$ & $1 \cdot 19,3 \cdot 30$ \\
\hline \multicolumn{10}{|l|}{ Fruit and vegetable intake } \\
\hline$<2$ servings/d ( $n$ 310) & 89 & $1 \cdot 00$ & Ref. & 71 & $1 \cdot 00$ & Ref. & 132 & 1.00 & Ref. \\
\hline$\geq 2$ servings/d ( $n$ 281) & 101 & $1 \cdot 10$ & $0 \cdot 75,1 \cdot 62$ & 80 & $1 \cdot 24$ & $0.81,1 \cdot 89$ & 127 & 0.98 & $0.67,1.44$ \\
\hline \multicolumn{10}{|l|}{ Currently smoke } \\
\hline No (n 468) & 152 & $1 \cdot 00$ & Ref. & 111 & $1 \cdot 00$ & Ref. & 200 & $1 \cdot 00$ & Ref. \\
\hline Yes (n 123) & 38 & 0.94 & $0.58,1.53$ & 40 & $1 \cdot 36$ & $0 \cdot 84,2 \cdot 21$ & 59 & $1 \cdot 30$ & $0 \cdot 83,2 \cdot 05$ \\
\hline BMI $\left(\mathrm{kg} / \mathrm{m}^{2}\right)$ & & $1 \cdot 00$ & $0.97,1.04$ & & $1 \cdot 06^{\star \star}$ & $1 \cdot 01,1 \cdot 10$ & & $1 \cdot 00$ & $0.96,1.03$ \\
\hline
\end{tabular}

Ref., referent category.

${ }^{\star} P<0.05 ;{ }^{\star *} P<0.01$.

tOdds ratio and $95 \%$ confidence intervals from logistic regression models, adjusted for all other variables in the table, weighted to the Sur City population, 2003. All $n$ values presented are unweighted $n$ within the sample.

¥Participants classified as 'inactive' according to domain as follows: work, lowest quartile; transport and leisure, no physical activity.

Table 3 Correlates of domain-specific physical inactivity in Omani women ( $n$ 744), Sur Healthy Lifestyle Survey, 2006t‡

\begin{tabular}{|c|c|c|c|c|c|c|c|c|c|}
\hline & \multicolumn{3}{|c|}{ Work } & \multicolumn{3}{|c|}{ Transport } & \multicolumn{3}{|c|}{ Leisure } \\
\hline & $n$ (inactive) & OR & $95 \% \mathrm{Cl}$ & $n$ (inactive) & OR & $95 \% \mathrm{Cl}$ & $n$ (inactive) & OR & $95 \% \mathrm{Cl}$ \\
\hline \multicolumn{10}{|l|}{ Age } \\
\hline $20-29$ years $(n 266)$ & 40 & $1 \cdot 00$ & Ref. & 106 & $1 \cdot 00$ & Ref. & 162 & $1 \cdot 00$ & Ref. \\
\hline $30-39$ years $(n$ 272) & 40 & $1 \cdot 09$ & $0 \cdot 63,1 \cdot 88$ & 88 & 0.77 & $0 \cdot 52,1 \cdot 16$ & 169 & 1.09 & $0.73,1.65$ \\
\hline$\geq 40$ years $(n 206)$ & 57 & $2 \cdot 29^{*}$ & $1 \cdot 14,4 \cdot 58$ & 62 & 0.91 & $0.52,1.59$ & 149 & $1 \cdot 56$ & $0 \cdot 86,2 \cdot 82$ \\
\hline$P$ for trend & & 0.03 & & & 0.44 & & & $0 \cdot 32$ & \\
\hline \multicolumn{10}{|l|}{ Education } \\
\hline Less than secondary ( $n$ 321) & 71 & $1 \cdot 00$ & Ref. & 96 & $1 \cdot 00$ & Ref. & 225 & $1 \cdot 00$ & Ref. \\
\hline Secondary ( $n$ 157) & 34 & $1 \cdot 64$ & $0.77,3.50$ & 49 & 0.97 & $0 \cdot 53,1 \cdot 76$ & 99 & $1 \cdot 37$ & $0.73,2 \cdot 55$ \\
\hline Post-secondary (n 266) & 32 & $1 \cdot 25$ & $0 \cdot 49,3 \cdot 17$ & 111 & 1.55 & $0 \cdot 81,2 \cdot 98$ & 156 & $1 \cdot 25$ & $0.63,2.48$ \\
\hline$P$ for trend & & $0 \cdot 39$ & & & $0 \cdot 24$ & & & $0 \cdot 62$ & \\
\hline \multicolumn{10}{|l|}{ Work status } \\
\hline Employed (n 310) & 37 & $1 \cdot 00$ & Ref. & 121 & $1 \cdot 00$ & Ref. & 178 & $1 \cdot 00$ & Ref. \\
\hline Not employed ( $n$ 434) & 100 & $1 \cdot 71$ & $0 \cdot 88,3 \cdot 35$ & 135 & $1 \cdot 01$ & $0 \cdot 60,1 \cdot 70$ & 302 & $1 \cdot 84^{\star}$ & $1 \cdot 08,3 \cdot 13$ \\
\hline \multicolumn{10}{|l|}{ Marital status } \\
\hline Not married (n 315) & 61 & $1 \cdot 00$ & Ref. & 110 & $1 \cdot 00$ & Ref. & 195 & $1 \cdot 00$ & Ref. \\
\hline Married (n 429) & 76 & $0 \cdot 67$ & $0 \cdot 43,1 \cdot 04$ & 146 & $1 \cdot 26$ & $0 \cdot 87,1 \cdot 82$ & 285 & $1 \cdot 13$ & $0.78,1 \cdot 64$ \\
\hline \multicolumn{10}{|l|}{ Fruit and vegetable intake } \\
\hline$<2$ servings/d ( $n$ 361) & 73 & $1 \cdot 00$ & Ref. & 105 & $1 \cdot 00$ & Ref. & 254 & $1 \cdot 00$ & Ref. \\
\hline$\geq 2$ servings/d ( $n$ 383) & 64 & $0 \cdot 91$ & $0.59,1.39$ & 151 & $1 \cdot 31$ & $0 \cdot 92,1 \cdot 85$ & 226 & $0 \cdot 63^{*}$ & $0.45,0.90$ \\
\hline BMI $\left(\mathrm{kg} / \mathrm{m}^{2}\right)$ & & $1 \cdot 01$ & $0.99,1.04$ & & 0.99 & $0.97,1.02$ & & $1 \cdot 00$ & $0.97,1.03$ \\
\hline
\end{tabular}

Ref., referent category.

${ }^{\star} P<0.05$.

tOdds ratio and $95 \%$ confidence intervals from logistic regression models, adjusted for all other variables in the table, weighted to the Sur City population, 2003. All $n$ values presented are unweighted $n$ within the sample.

‡Participants classified as 'inactive' according to domain as follows: work, lowest quartile; transport and leisure, no physical activity.

cohort. No potential correlates had significant associations with transport inactivity. For leisure inactivity, work status and fruit and vegetable intake were significant correlates (both $P<0 \cdot 05$ ): the odds of leisure inactivity were approximately $1 \cdot 8$-fold higher in women who were not employed $v$. those employed and approximately $1 \cdot 6$-fold lower for women consuming at least two servings of fruits and vegetables daily $v$. those not. For women 
Table 4 Correlates of sitting time (natural logarithm) in Omani men and women, Sur Healthy Lifestyle Survey, 2006

\begin{tabular}{|c|c|c|c|c|c|c|}
\hline & \multicolumn{3}{|c|}{ Men } & \multicolumn{3}{|c|}{ Women } \\
\hline & $n+$ & $\exp (b) \ddagger$ & $95 \% \mathrm{Cl}$ & $n+$ & $\exp (b) \ddagger$ & $95 \% \mathrm{Cl}$ \\
\hline \multicolumn{7}{|l|}{ Age } \\
\hline 20-29 years & 197 & $1 \cdot 00$ & Ref. & 266 & $1 \cdot 00$ & Ref. \\
\hline 30-39 years & 177 & 1.07 & $0 \cdot 88,1 \cdot 28$ & 272 & $0 \cdot 81^{\star *}$ & $0.69,0.94$ \\
\hline$\geq 40$ years & 217 & 1.04 & $0.83,1.31$ & 206 & $0 \cdot 71^{\star \star}$ & $0.57,0.88$ \\
\hline$P$ for trend & \multicolumn{3}{|c|}{0.688} & \multicolumn{3}{|c|}{0.001} \\
\hline \multicolumn{7}{|l|}{ Education } \\
\hline Less than secondary & 243 & $1 \cdot 00$ & Ref. & 321 & 1.00 & Ref. \\
\hline Secondary & 221 & $1 \cdot 20$ & $0.98,1.46$ & 157 & 0.85 & $0.68,1.06$ \\
\hline Post-secondary & 127 & $1 \cdot 32^{*}$ & $1.06,1.65$ & 266 & 0.99 & $0 \cdot 76,1 \cdot 29$ \\
\hline$P$ for trend & \multicolumn{3}{|c|}{0.013} & \multicolumn{3}{|c|}{0.962} \\
\hline \multicolumn{7}{|l|}{ Work status } \\
\hline Employed & 461 & 1.00 & Ref. & 310 & $1 \cdot 00$ & Ref. \\
\hline Not employed & 130 & 1.03 & $0.87,1.22$ & 434 & $1 \cdot 49^{\star \star}$ & $1 \cdot 18,1 \cdot 8 s$ \\
\hline \multicolumn{7}{|l|}{ Marital status } \\
\hline Not married & 198 & 1 & Ref. & 315 & 1 & Ref. \\
\hline Married & 393 & 1.08 & $0.91,1.29$ & 429 & 0.99 & $0 \cdot 85,1 \cdot 15$ \\
\hline \multicolumn{7}{|l|}{ Fruit and vegetable intake } \\
\hline$<2$ servings/d & 310 & 1.00 & Ref. & 361 & $1 \cdot 00$ & Ref. \\
\hline$\geq 2$ servings/d & 281 & 0.98 & $0 \cdot 85,1 \cdot 13$ & 383 & 0.91 & $0.79,1.05$ \\
\hline BMI $\left(\mathrm{kg} / \mathrm{m}^{2}\right)$ & 591 & 1.00 & $0.99,1.02$ & 744 & $1 \cdot 01^{*}$ & $1.00,1.02$ \\
\hline
\end{tabular}

Ref., referent category.

${ }^{\star} P<0.05 ;{ }^{\star \star} P<0.01$.

tUnweighted $n$.

¥Regression coefficient, back-transformed from the log scale weighted to the Sur City population, 2003; represents the ratio of sitting time relative to the referent group (categorical variables) or of a one unit increase (continuous variables).

overall in Sur City, the adjusted prevalence (95\% CI) for work inactivity was $20 \cdot 4(95 \%$ CI $17 \cdot 5,23 \cdot 3) \%, 33 \cdot 9(95 \%$ CI $30 \cdot 5,37 \cdot 3) \%$ for transport inactivity and $65 \cdot 7$ (95\% CI $62 \cdot 2,69 \cdot 1) \%$ for leisure inactivity. Adjusted prevalence (95\% CI) across the identified correlates showed that the subgroups of women who were often 'inactive' were women aged $\geq 40$ years (28.7 (95\% CI $20 \cdot 0,37 \cdot 4$ ) \% for work inactivity), who were not employed ( $71 \cdot 0$ (95\% CI $65 \cdot 5,76 \cdot 4) \%$ for leisure inactivity) and who consumed less than two servings of fruit and vegetables daily (71.2 (95\% CI $65 \cdot 9,76 \cdot 5) \%$ for leisure inactivity).

Table 4 shows the correlates of sitting time. For men, there was only one significant correlate of sitting time ( $P$ for trend $=0 \cdot 013$ ): compared with those with less than secondary education, sitting time was relatively higher by $20 \%$ in men with secondary education and by $32 \%$ in men with post-secondary education. There was no evidence of an association of smoking or age with sitting time overall; however, the association of smoking with sitting time differed by age ( $P$ for interaction $=0 \cdot 02$ ) Using an additional model that included an interaction term for these variables, there was no association of smoking with sitting time in men aged 20-29 years and $\geq 40$ years; however, in men aged 30-39 years, smokers had significantly higher mean sitting time than their nonsmoking counterparts (215 (95\% CI 167, 277) $\mathrm{min} / \mathrm{d} v$. 149 (95\% CI 129, 173) $\mathrm{min} / \mathrm{d} ; P<0 \cdot 05$; data not shown). The overall mean sitting time of men in Sur City was 157 (95\% CI 147, 168) $\mathrm{min} / \mathrm{d}$. Looking at the marginal means for the identified correlates revealed some groups of men with high sitting time, including those with post-secondary education (182 (95\% CI 157, 211) $\mathrm{min} / \mathrm{d}$ ) and smokers aged 30-39 years (215 (95\% CI 167, 277) $\min / \mathrm{d}$ ).

For women, age, employment status and BMI were significantly associated with sitting time. Age was inversely associated with sitting time: compared with women aged 20-29 years, sitting time was relatively lower by $23 \%$ in women aged $30-39$ years $(\exp (b)=0 \cdot 81,95 \%$ CI $0 \cdot 69$, $0.94 ; P<0.001)$ and by $41 \%$ in women aged $\geq 40$ years $(\exp (b)=0 \cdot 71,95 \%$ CI $0 \cdot 57,0 \cdot 88 ; P<0 \cdot 001)$. Sitting time was relatively higher by $49 \%$ in employed women compared with women who were not employed $(\exp (b)=$ $1 \cdot 49,95 \%$ CI $1 \cdot 18,1 \cdot 89 ; P<0 \cdot 01)$. In women, for every unit increase in BMI, there was a significant increase in sitting time $(P<0 \cdot 05)$. The overall mean sitting time for women in Sur City was 122 (95\% CI 115, 130) $\mathrm{min} / \mathrm{d}$. Marginal means across the identified correlates showed high levels of sitting in certain groups of women: those aged 20-29 years (143 (95\% CI 127, 161) $\mathrm{min} / \mathrm{d})$, those who were not employed (141 (95\% CI 126, 158) $\mathrm{min} / \mathrm{d}$ ) and those who were obese (140 (95\% CI 126, 156) $\mathrm{min} / \mathrm{d})$.

\section{Discussion}

The present examination of the sociodemographic, anthropometric and behavioural correlates of physical inactivity and sitting time is one of the few available for a population from the Arabian Gulf and one of the few available internationally using the GPAQ. The population was most inactive in the leisure domain, compared with 
the transport and leisure domains, similar to some countries in Asia and Africa ${ }^{(21-24)}$. Sitting time in our study was less than what has been reported in many other countries $^{(14,24,25)}$. All attributes studied showed a significant association with at least one domain of physical inactivity or sitting time and differed by gender, domainspecific physical inactivity and sitting time. The gender variations highlight the importance of understanding the conservative cultural norms which influence how men and women can be physically active.

Evidence from developed countries, most of which addresses leisure-time physical activity, indicates that older age is associated with being less active ${ }^{(11,12)}$. However, evidence on overall levels of physical inactivity (which includes physical activity from all three domains) paints an inconsistent picture. There is an increase in physical inactivity with age in both developed and developing countries, particularly in men. On the other hand, inactivity does not vary with age in some rural populations in Asia ${ }^{(22)}$, and in Ho Chi Min City, Vietnam, specifically ${ }^{(23)}$. In some countries, such as New Zealand, both men and women in all age groups are, in general, physically active ${ }^{(26)}$. In the present study, older Omani women were less active in the work domain compared with their younger counterparts. One explanation for this may be that younger women may be carrying the double burden of both formal employment (i.e. in professions that require long periods of standing/walking such as teaching and nursing) as well as household/family responsibilities, unlike women over 40 years of age who generally are not part of the formal employment sector ${ }^{(27)}$. That younger age is associated with transport inactivity among men in Sur City may be a reflection of the cohort effect with older men possibly being more accustomed to regular active transport, bearing in mind that widespread car ownership is a relatively recent phenomenon ${ }^{(28)}$.

Many studies from developed countries have reported that people with less education have higher odds of being physically inactive ${ }^{(11,12)}$; such an association was seen only among men in our study. However, similar to age, global evidence on the associations of education with physical activity is inconsistent ${ }^{(22,29)}$. Studies in South-East Asia have found that those with less education are more active $^{(22,23)}$, highly educated individuals in China were less active during work and transport but more active during leisure compared with those less educated, but in the Philippines, Malaysia and Nauru there was no association between education and physical activity ${ }^{(29)}$. Given that the association of education with physical inactivity appears to be context specific, and due to some of the inconclusive findings for the Sur population, further research is needed to better understand this relationship in Oman.

One of the most interesting findings from the current study is that men and women who were not employed were at significantly higher odds of leisure inactivity; a finding seen in some developed countries ${ }^{(30-32)}$ but not others $^{(33,34)}$. In our study, those who were not employed were diverse (i.e. students, job seekers, housewives and retirees); barriers and supports for physical inactivity likely vary for each of these different groups. Thus, further research about the non-working population would be useful to shape appropriate public health interventions.

Associations of the other correlates identified in the present study (marital status, diet and BMI) have been reported elsewhere ${ }^{(11,12)}$. Studies have noted the clustering of risk behaviours such as physical inactivity with low fruit and vegetable intake ${ }^{(30,35)}$ which suggests that public health interventions might target both behavioural risk factors together. The association of higher BMI with transport inactivity in men suggests that the promotion of physically active transport (such as the provision of sidewalks in residential areas to improve access to neighbourhood mosques and grocery stores) could be considered a potential obesity prevention/management strategy.

A unique contribution of the current study is the evaluation of the correlates of sitting time, an area with limited available evidence ${ }^{(13)}$. The finding that younger women have higher sitting times than older women was seen in ten of eighteen countries in the International Prevalence Study (IPS) ${ }^{(14)}$ and in a study in Australia ${ }^{(36)}$; however, a study in the USA showed that sedentary time increased with age for both men and women ${ }^{(37)}$. The result that more-educated men have higher sitting times than those less educated was also observed in fifteen of nineteen countries in the IPS ${ }^{(14)}$ but not in a study in Australia $^{(36)}$. Some of the other correlates identified in our study (employment status, smoking and BMI) have been reported to be associated with television viewing time in populations in Australia and the $\mathrm{USA}^{(38,39)}$. Recent evidence indicates that the relevant correlates can vary depending on the type of sedentary behaviour ${ }^{(36,38,39)}$; thus, further research on the correlates of domain-specific sedentary behaviours is required.

Although our study had a high response rate (80\%) and data were weighted to the Sur population, the generalizability of the results within Sur itself is limited by the fact that information regarding population clusters and nonrespondents was not available at the time of analysis. Since the study was only of the adult population in Sur, generalizability nationally or to neighbouring countries may also be limited. The sample size - while not planned a priori for the research questions that we address appears adequate for sitting time; either the sitting time findings showed a 'significant' correlate of sitting time or null results showed any sizeable association to be unlikely (i.e. confidence intervals always ruled out sizeable effects, defined as a twofold relative rate or odds ratio). For physical inactivity, larger samples are needed to ensure adequate power to provide definitive results, as null results were sometimes inconclusive, neither showing a significant association nor ruling out sizeable effects (here, a doubling/halving in odds). Given (i) that the 
GPAQ has not been validated for an Arab population ${ }^{(19)}$, (ii) the error associated with self-reported measures of physical activity and sitting time and (ii) that the Sur questionnaire does not explicitly provide guidance to the interviewee on potentially confusing phrases (i.e. 'moderate-intensity physical activity' and 'sitting time') $)^{(37)}$, it is possible that some people have been misclassified for domain-specific physical activity and that the reported sitting is over- or underestimated. The associations reported do not denote causality owing to the crosssectional nature of the study.

Measurement limitations need to be addressed in order to improve population-based surveys in Arab countries. For example, the GPAQ, which is a part of the STEPwise instrument, has been tested for validity in some developed countries but not with Arab populations. Device-based measurement would be preferable, but has not yet been used in population-based surveys in the Arabian Gulf region. Given that the WHO STEPwise approach has been used in several Arab countries, it appears to be the best option available at this time.

\section{Conclusions}

The present study is the first to report on the correlates of physical inactivity and sitting time for a population-based survey in the Arabian Gulf. Key population demographic subgroups with a particularly high prevalence of physical inactivity were men and women who were not employed, women aged $\geq 40$ years, men aged 20-29 years and men who were married; those with high mean levels of sitting time were women aged 20-29 years, women who were not working and men with post-secondary education. Further information regarding the barriers and supports for these behaviours, particularly for the high-risk demographic groups, is required to shape public health policy and programme interventions. BMI had associations only with transport inactivity in men and sitting time in women, pointing to the need to explore the possibility of active transport and reductions in sitting time as potential obesity prevention/management strategies for this population. With over half of the population of Sur City and nearly three-quarters of non-working women doing no leisure-time physical activity at all, promotion of leisure-time physical activity is an important goal.

These findings can help to inform the targeting of public health interventions to reduce physical inactivity and sitting time. Given the varied patterns of associations by gender and by work, transport and leisure physical activity, public health interventions may need to be gender specific and focus on domain-specific physical activity, such as establishing gender-segregated exercise facilities to promote leisure-time physical activity among women and building walker-friendly neighbourhoods to promote transport physical activity among men. Because of the high prevalence of overweight/obesity in Oman and the Arabian Gulf ${ }^{(28,40)}$, promoting physical activity, particularly among high-risk groups, is a priority. Since continued socio-economic development in Oman may lead to increases in work and transport inactivity and more prolonged sitting time, creating activity-supportive environments is an important population health strategy.

\section{Acknowledgements}

E.A.H.W., E.G.E., M.M.R. and N.O. are supported by Programme and Fellowship Grants from the National Health and Medical Research Council of Australia and by Research Infrastructure funding from Queensland Health. N.O. is also supported by Research Infrastructure funding from the Victorian Government. The authors declare to have no conflicts of interest. R.M.M. carried out the secondary analysis and writing of the manuscript; E.G.E. supervised the manuscript writing and manuscript editing; E.A.H.W. supervised the statistical analysis and editing of the Methods and Results sections of the manuscript; M.M.R. assisted with the statistical analysis and manuscript writing; N.O. assisted with the manuscript writing and manuscript editing. The authors thank the Director General of Health Service, A'Sharqiyah Region, Ministry of Health, Oman and those involved with the Sur Healthy City Project for their willingness to share their data.

\section{References}

1. Haskell WL, Lee IM, Pate RR et al. (2007) Physical activity and public health: updated recommendation for adults from the American College of Sports Medicine and the American Heart Association. Circulation 116, 1081-1093.

2. World Health Organization (2002) Reducing Risks, Promoting Healthy Life. World Health Report 2002. Geneva: WHO.

3. World Health Organization (2005) Preventing Chronic Diseases: A Vital Investment. Geneva: WHO.

4. Dunstan DW, Salmon J, Owen N et al. (2005) Associations of TV viewing and physical activity with the metabolic syndrome in Australian adults. Diabetologia 48, 2254-2261.

5. Healy GN, Wijndaele K, Dunstan DW et al. (2008) Objectively measured sedentary time, physical activity, and metabolic risk: the Australian Diabetes, Obesity and Lifestyle Study (AusDiab). Diabetes Care 31, 369-371.

6. Ford ES, Kohl HW 3rd, Mokdad AH et al. (2005) Sedentary behavior, physical activity, and the metabolic syndrome among US adults. Obes Res 13, 608-614.

7. Katzmarzyk PT, Church TS, Craig CL et al. (2009) Sitting time and mortality from all causes, cardiovascular disease, and cancer. Med Sci Sports Exerc 41, 998-1005.

8. Dunstan DW, Barr EL, Healy GN et al. (2010) Television viewing time and mortality: the Australian Diabetes, Obesity and Lifestyle Study (AusDiab). Circulation 121, 384-391.

9. Mabry RM, Winkler EA, Reeves MM et al. (2012) Associations of physical activity and sitting time with the metabolic syndrome among Omani adults. Obesity (Silver Spring) (Epublication ahead of print version).

10. Al-Lawati JA, Mabry R \& Mohammed AJ (2008) Addressing the threat of chronic diseases in Oman. Prev Chronic Dis 5. A99. 
11. Bauman AE, Sallis JF, Dzewaltowski DA et al. (2002) Toward a better understanding of the influences on physical activity: the role of determinants, correlates, causal variables, mediators, moderators, and confounders. Am J Prev Med 23, 5-14.

12. Trost SG, Owen N, Bauman AE et al. (2002) Correlates of adults' participation in physical activity: review and update. Med Sci Sports Exerc 34, 1996-2001.

13. Owen N, Sugiyama T, Eakin EE et al. (2011) Adults' sedentary behavior determinants and interventions. $\mathrm{Am} \mathrm{J}$ Prev Med 41, 189-196.

14. Bauman A, Ainsworth BE, Sallis JF et al. (2011) The descriptive epidemiology of sitting. A 20-country comparison using the International Physical Activity Questionnaire (IPAQ). Am J Prev Med 41, 228-235.

15. World Health Organization (2005) WHO STEPS Surveillance Manual: The WHO STEPwise Approach to Chronic Disease Risk Factor Surveillance. Geneva: WHO.

16. Ministry of National Economy (2003) Final Results of the Census 2003. Muscat, Oman: Ministry of National Economy.

17. World Health Organization (2008) Global Physical Activity Questionnaire (GPAQ) Analysis Guide. Geneva: WHO.

18. Armstrong T \& Bull F (2006) Development of the World Health Organization Global Physical Activity Questionnaire (GPAQ). J Public Health 14, 66-70.

19. Bull FC, Maslin TS \& Armstrong T (2009) Global physical activity questionnaire (GPAQ): nine country reliability and validity study. J Phys Act Health 6, 790-804.

20. Trinh OT, Nguyen ND, van der Ploeg HP et al. (2009) Test-retest repeatability and relative validity of the Global Physical Activity Questionnaire in a developing country context. J Phys Act Health 6, Suppl. 1, S46-S53.

21. Guthold R, Louazani SA, Riley LM et al. (2011) Physical activity in 22 African countries: results from the World Health Organization STEPwise approach to chronic disease risk factor surveillance. Am J Prev Med 41, 52-60.

22. Ng N, Hakimi M, Van Minh H et al. (2009) Prevalence of physical inactivity in nine rural INDEPTH Health and Demographic Surveillance Systems in five Asian countries. Glob Health Action 2, doi: 10.3402/gha.v2i0.1985.

23. Trinh OT, Nguyen ND, Dibley MJ et al. (2008) The prevalence and correlates of physical inactivity among adults in Ho Chi Minh City. BMC Public Health 8, 204.

24. Ministry of Health Kuwait (2006) WHO STEPwise Approach to NCD Surveillance, Kuwait. Kuwait City, Kuwait: Ministry of Health, Kuwait in collaboration with WHO.

25. Ministry of Health Saudi Arabia (2005) WHO Stepwise Approach to NCD Surveillance, Saudi Arabia. Riyadh, Saudi Arabia: Ministry of Health in collaboration with WHO, EMRO.
26. Bauman A, Bull F, Chey T et al. (2009) The International Prevalence Study on Physical Activity: results from 20 countries. Int J Behav Nutr Phys Act 6, 21.

27. Ministry of Health (2000) National Health Survey, Volume 1, Study of Life Style Risk Factors. Muscat, Oman: Ministry of Health.

28. Al-Lawati JA \& Jousilahti PJ (2004) Prevalence and 10-year secular trend of obesity in Oman. Saudi Med J 25, 346-351.

29. Bauman A, Ma G, Cuevas F et al. (2011) Cross-national comparisons of socioeconomic differences in the prevalence of leisure-time and occupational physical activity, and active commuting in six Asia-Pacific countries. J Epidemiol Community Health 65, 35-43.

30. Bopp M, Wilcox S, Laken M et al. (2006) Factors associated with physical activity among African-American men and women. Am J Prev Med 30, 340-346.

31. Van Domelen DR, Koster A, Caserotti P et al. (2011) Employment and physical activity in the US. Am J Prev Med 41, 136-145.

32. Slingerland AS, van Lenthe FJ, Jukema JW et al. (2007) Aging, retirement, and changes in physical activity: prospective cohort findings from the GLOBE study. Am J Epidemiol 165, 1356-1363.

33. Shibata A, Oka K, Nakamura Y et al. (2009) Prevalence and demographic correlates of meeting the physical activity recommendation among Japanese adults. J Phys Act Health 6, 24-32.

34. Allender S, Hutchinson L \& Foster C (2008) Life-change events and participation in physical activity: a systematic review. Health Promot Int 23, 160-172.

35. Hausdorf K, Eakin E, Whiteman D et al. (2008) Prevalence and correlates of multiple cancer risk behaviors in an Australian population-based survey: results from the Queensland Cancer Risk Study. Cancer Causes Control 19, 1339-1347.

36. Salmon J, Owen N, Crawford D et al. (2003) Physical activity and sedentary behavior: a population-based study of barriers, enjoyment, and preference. Health Psychol 22, 178-188.

37. Healy GN, Clark BK, Winkler EA et al. (2011) Measurement of adults' sedentary time in population-based studies. $\mathrm{Am} \mathrm{J}$ Prev Med 41, 216-227.

38. King AC, Goldberg JH, Salmon J et al. (2010) Identifying subgroups of US adults at risk for prolonged television viewing to inform program development. Am J Prev Med 38, $17-26$.

39. Clark BK, Sugiyama T, Healy GN et al. (2010) Sociodemographic correlates of prolonged television viewing time in Australian men and women: the AusDiab study. J Phys Act Health 7, 595-601.

40. Ng SW, Zaghloul S, Ali HI et al. (2011) The prevalence and trends of overweight, obesity and nutrition-related non-communicable diseases in the Arabian Gulf States. Obes Rev 12, 1-13. 